\title{
ALINHAMENTO ESTRATÉGICO DA TECNOLOGIA DA INFORMAÇÃO AOS NEGÓCIOS DE UMA PEQUENA EMPRESA DE SOFTWARE.
}

\section{STRATEGICAL ALIGNMENT OF THE INFORMATION TECHNOLOGY TO SMALL SOFTWARE'S COMPANY BUSINESS.}

\author{
Érika Suzuki \\ Pós-Graduanda \\ Universidade Federal de Santa Catarina \\ Engenharia e Gestão do Conhecimento \\ Rua Deputado Antônio Edu Vieira, 65, 104-D \\ Pantanal - Florianópolis, SC, 88040-000 \\ (48) 32220041 erika.suzuki@gmail.com
}

\author{
Aline França de Abreu \\ Professora e Pesquisadora \\ Universidade Federal de Santa Catarina \\ Engenharia de Produção e Sistemas \\ Cx. Postal 476 - Campus Universitário - Florianópolis - SC
}

(48) 3317106 aline@ deps.ufsc.br

\section{Pedro Felipe de Abreu}

\author{
Consultor
}

Arte Factu TI LTDA.

Rod. SC 403 - Km 3, 2565

V. Bom Jesus - Florianópolis, SC, 88058-500

(48) 2667078 - pedro@ artefactu.com.br 


\title{
RESUMO
}

Atualmente, com as inovações tecnológicas, o alto investimento das empresas em modernização, a procura por soluções inteligentes, bem como a alta competitividade do mercado em geral, tornam fundamental a adoção de ferramentas, soluções e produtos que destaquem a empresa nesse mercado tão competitivo. Porém, a rápida adoção dessas soluções pode ocasionar o crescimento desordenado de setores, compras e aquisição de recursos desnecessários, sendo que o planejamento estratégico se configura em solução eficaz para a maioria desses problemas. Entretanto, para pequenas empresas de desenvolvimento de software há uma grande dificuldade na adoção de uma metodologia que seja aplicável à sua realidade. Seguindo este ponto de vista, o presente artigo propõe um modelo que ofereça à empresa a prática do planejamento estratégico focado na Tecnologia da Informação de forma simplificada e compreensível, tornando visíveis os benefícios, problemas, soluções e o aprendizado que um planejamento estratégico pode oferecer, considerando também aspectos como custo, tempo e grau de formalização, pois o maior problema para as pequenas empresas é a baixa possibilidade de investimento das mesmas na implementação de um planejamento estratégico, e o curto tempo de resposta que as mesmas esperam obter.

Palavras-chave: Planejamento, alinhamento, tecnologia da informação.

\begin{abstract}
Currently with the technological innovations, the high investment of the companies with the modernization, the search for intelligent solutions, the high competitiveness of the market in general, they together are the tools, solutions and products required by companies that want to stand out in the competitive market, however, the fast adoption of these solutions could cause a disordered growth of sectors, purchases and acquisitions of unnecessary resources, on the other hand, with a strategical planning the majority of these problems could be eliminated. Small software's companies have great difficulty in adopting a methodology that can be applied to its reality. Following this point of view, the present paper proposes a model that offers a pratical strategical planning to companies that focus the Information Technology in a simplified and understandable way, making visible the benefits, problems, solutions and the learning that a strategical planning can offer, considering also aspects such as cost, time and formalization degree was important, because the biggest problems to small software companies are their small budget to implement a strategical planning and their expectation for a short answer time.
\end{abstract}

Key-words: Planning, alignment, information technology.

\section{INTRODUÇÃO}


Este trabalho apresentará um modelo proposto que objetiva o alinhamento estratégico da Tecnologia da Informação aos negócios de uma pequena empresa de desenvolvimento de software e a avaliação de sua aplicabilidade através de um estudo de caso. O modelo baseia-se em uma metodologia de gestão estratégica combinada a uma metodologia de planejamento estratégico de Tecnologia da Informação (TI), procurando obter o alinhamento entre os negócios e atividades de uma pequena empresa de desenvolvimento de software. Porém é válido ressaltar que, com a implantação do planejamento estratégico, torna-se necessária uma mudança de cultura dentro da organização, a fim de que a mesma alcance os objetivos propostos.

A TI tornou-se um instrumento essencial para as empresas que procuram se destacar e sobreviver no mercado competitivo, porém para a obtenção de um diferencial estratégico e para o gerenciamento da informação é necessário que seja elaborado um plano detalhado que contenha os passos a serem seguidos, os objetivos a serem alcançados, um cronograma que destaque os aspectos essenciais dos negócios e as tecnologias disponíveis e emergentes.

De acordo com Kaplan e Norton em "A Estratégia em Ação - Balanced Scorecard” (1997, p.3) “... o advento da era da informação nas últimas décadas do século XX tornou obsoletas muitas das premissas fundamentais da concorrência industrial. As empresas não conseguem mais obter vantagens competitivas sustentáveis apenas com a rápida alocação de novas tecnologias a ativos físicos, e com a excelência da gestão eficaz dos ativos e passivos financeiros”. Ainda segundo os autores (1997, p.19) “...A inovação e a melhoria de produtos, serviços e processos nascerão da reciclagem dos funcionários, pelo uso de tecnologias de informações e de procedimentos organizacionais estrategicamente alinhados".

A inexistência de um planejamento estratégico, a não integração da estratégia global da empresa com os sistemas de informação, entre outros, pode ocasionar, além da perda de lucros, a não otimização da produção e diversos sistemas independentes (não integrados), que poderão gerar um retorno menor do que aquele esperado pela empresa.

Segundo Beal (2001), planejar significa estabelecer o que se vai fazer (atividades, objetivos, decisões), com quem fazer (recursos humanos), quando fazer (datas de início e término) e com o que fazer (recursos tecnológicos, financeiros etc.). E com a grande difusão da tecnologia da informação nos diversos níveis e áreas de negócios das empresas, a necessidade de que se faça um planejamento não só empresarial como também para a informação corporativa, torna-se essencial para garantir que possam ser desenvolvidos planos de sistemas e bases de dados que atendam às necessidades de informação da organização como um todo. Ainda segundo a autora, o planejamento estratégico é a etapa inicial da gestão 
da tecnologia da informação, permitindo que se estabeleçam os propósitos básicos para que a empresa possa implantar sistemas informatizados estáveis e benéficos para o desempenho das atividades operacionais e de apoio à tomada de decisões.

A aplicação de uma Metodologia de Planejamento Estratégico da Informação garante os seguintes resultados (FORMA, 2003):

- Determinação de um caminho consistente e específico que conduza ao uso da TI como um diferencial competitivo;

- Desenvolvimento de projetos vinculados a TI, integrados, não redundantes, com objetivo final comum;

- Possibilidade de um gerenciamento integrado dos projetos

- Planejamento de recursos humanos vinculados a TI;

- Previsão de custos associados a TI;

- Integração efetiva entre a Área de Informática e as Áreas de Negócio.

\section{MODELOS}

Dentre os vários modelos existentes de Estratégia como: Fernandes \& Alves (1992), Michael Treacy (1995), Turban (1996), Kaplan \& Norton (1997), entre outros analisados em SUZUKI (2004); dois foram escolhidos como base para o modelo proposto, pois são objetivos, de fácil compreensão e de maior aplicabilidade na prática, facilitando o processo de implantação dentro de uma empresa, oferecendo um diagnóstico do projeto organizacional e identificando o papel da TI nos processos.

O modelo de Porter (1979) é referenciado por muitos dos modelos analisados, entretanto Mintzberg (1988) confronta o modelo sugerindo cinco definições (agrupamentos de famílias de estratégias): Plano, Trama, Padrão, Posição e Perspectiva. No Plano a estratégia procura estabelecer direções para a organização; na Trama a estratégia é aplicada para confundir e ameaçar os concorrentes; o ganho de vantagem é a estratégia aplicada na Busca, onde a organização pode utilizar estratégias de penetração, desenvolvimento de mercado e/ou produtos; já no Padrão a estratégia considera o comportamento e a assimilação de ações de sucesso no processo decisório da organização; na Posição, a estratégia encoraja as organizações a analisarem o ambiente procurando defender-se e influenciar a competição; e por fim na Perspectiva a estratégia foca a intenção e comportamento em um contexto coletivo. 
Dos modelos escolhidos, o Balanced Scorecard (Kaplan e Norton, 1997) busca traduzir a missão e a estratégia da empresa em objetivos e medidas tangíveis. A missão e a estratégia são traduzidas em objetivos e medidas segundo quatro diferentes perspectivas: financeira, do cliente, dos processos internos e do aprendizado e crescimento. $\mathrm{O}$ modelo de Fernandes \& Alves (1992), baseado no modelo das Forças Competitivas e na Cadeia de Valor de Porter (1985); define as estratégias com o uso da TI, em que os níveis de abstração sobre o planejamento estão mais detalhados e mais claros, além de fornecer também um check-list do processo, facilitando a definição de ações.

\subsection{Balanced Scorecard}

Conforme citado anteriormente, a proposta do Balanced Scorecard (BSC) é traduzir a missão e a estratégia de uma unidade de negócios em objetivos e medidas tangíveis. As medidas representam o equilíbrio entre indicadores internos e externos voltados para acionistas e clientes e para as medidas internas de processos críticos de negócios, inovação, aprendizado e crescimento. O BSC é mais do que um sistema de medidas táticas ou operacionais, ele é usado por algumas empresas como um sistema de gestão estratégica em longo prazo, viabilizando, dessa forma, processos gerenciais críticos como, esclarecer e traduzir a visão e a estratégia; comunicar e associar objetivos e medidas estratégicas; planejar, estabelecer metas e alinhar iniciativas estratégicas e melhorar o feedback e o aprendizado estratégico. A tradução da estratégia sobre as quatro perspectivas do BSC pode ser visualizada através da figura 1.

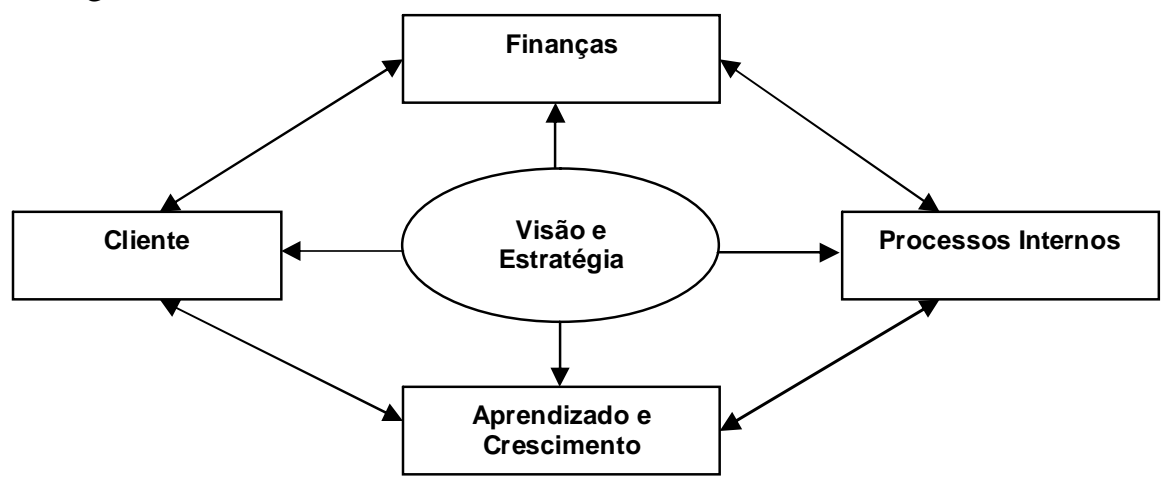

Figura 1: Estrutura necessária fornecida pelo Balanced Scorecard, para a tradução da estratégia em termos operacionais. 
Fonte: A Estratégia em Ação - Balanced Scorecard (1997, p. 10)

O BSC pode ser utilizado para esclarecer e obter consenso em relação à estratégia; comunicar a estratégia à toda a empresa; alinhar as metas departamentais e pessoais à estratégia; associar os objetivos estratégicos com metas de longo prazo e orçamentos anuais; identificar e alinhar as iniciativas estratégicas; realizar revisões estratégicas periódicas e sistemáticas; obter feedback para aprofundar o conhecimento da estratégia e aperfeiçoá-la.

Com vimos, a missão e a estratégia são traduzidas em objetivos e medidas, segundo quatro diferentes perspectivas: financeira, do cliente, dos processos internos e do aprendizado e crescimento. Um BSC bem elaborado deverá contar a história da estratégia da unidade de negócios, identificando e tornando explícita a seqüência de hipóteses sobre as relações de causa e efeito entre as medidas de resultado e os vetores de desempenho desses resultados. Toda medida selecionada para um BSC deve ser um elemento integrante da cadeia de relações de causa e efeito que comunica o significado da estratégia da unidade de negócios à organização. A relação de causa e efeito, comunicando todas as perspectivas do BSC pode ser vista na figura 2.

\section{Perspectivas do BSC}

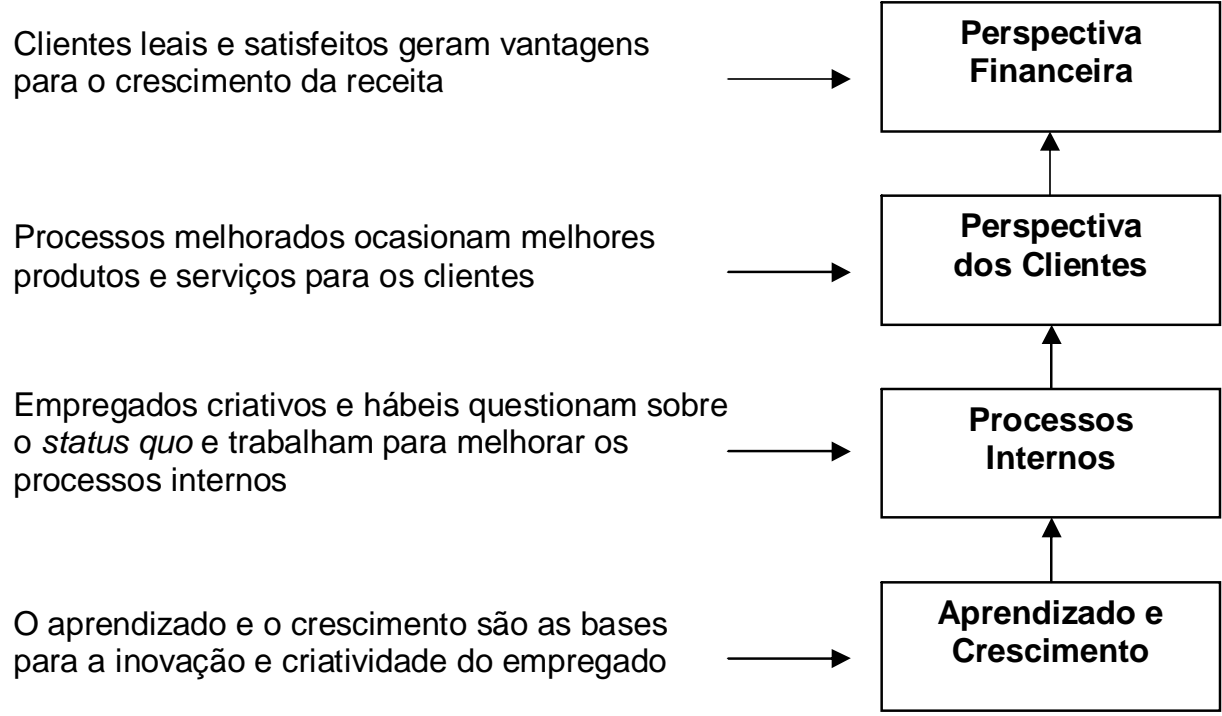

Figura 2: Relações de causa e efeito das perspectivas do Balanced Scorecard (figura adaptada) Fonte: Balanced Scorecard Institute (2005) 
Quadro 1: As quatro perspectivas do Balanced Scorecard.

\begin{tabular}{|l|l|}
\hline Perspectiva & Medidas Genéricas \\
\hline Financeira & Retorno sobre o investimento e o valor econômico agregados. \\
\hline Do cliente & Satisfação, retenção, participação de mercado e participação nas contas. \\
\hline Interna & Qualidade, tempo de resposta, custo e lançamentos de novos produtos. \\
\hline $\begin{array}{l}\text { Aprendizado e } \\
\text { Crescimento }\end{array}$ & Satisfação dos funcionários e disponibilidade dos sistemas de informação. \\
\hline
\end{tabular}

\subsection{Modelo de Fernandes \& Alves}

O Modelo de Fernandes \& Alves (1992), parte dos Modelos de Forças Competitivas e da Cadeia de Valor de Porter (1985), que visam estratégias organizacionais aliadas às estratégias de Tecnologia de Informação. O Modelo é composto de três etapas:

\section{a. identificação da natureza das forças competitivas da organização:}

Baseados na Análise das Forças Competitivas (Porter, 1985), Fernandes \& Alves (1992) sugerem um esquema de referência para que se avalie a importância de cada uma das forças competitivas para uma organização em cada linha de negócio.

\section{b. definição das estratégias para a organização:}

Segundo Fernandes \& Alves (1992), toda organização adota estratégias para atingir seus objetivos, visando direcionar e coordenar esforços, definir a organização e sobreviver em ambientes hostis. O autor classifica as estratégias em dois grandes grupos: Estratégias de crescimento e Estratégias competitivas.

\section{c. identificação do suporte da TI às estratégias propostas pela organização:}

> análise dos impactos da TI:

Para Fernandes \&Alves (1992), o impacto da TI pode ser visualizado em quatro níveis, sendo que se deve avaliar o impacto da implantação da TI em cada um destes níveis, podendo ser adaptado a cada caso. Os níveis são: indústria ou setor de atuação, forças competitivas, estratégias e operações/produtos. 
> grau de dependência estratégica da organização com relação a TI:

Segundo os autores, o grau de dependência da organização em relação a TI vai depender dos seguintes fatores: maturidade da empresa com o uso da TI, imposição do mercado ou ramo de negócios, ações gerenciais e natureza dos produtos/serviços produzidos pela empresa. Uma das formas de avaliar a dependência de uma empresa em relação a TI é através da Matriz de Dependência Estratégica proposta por McFarlan (FERNANDES \& ALVES, 1992, p.35). A Matriz busca avaliar o tipo de dependência que a empresa possui em relação à tecnologia, e as implicações para a área de TI da mesma. A mudança de quadrantes na Matriz ocorre no sentido: apoio $\rightarrow$ mudanças $\rightarrow$ manutenção do crescimento $\rightarrow$ estratégico, como podemos visualizar na figura 3:

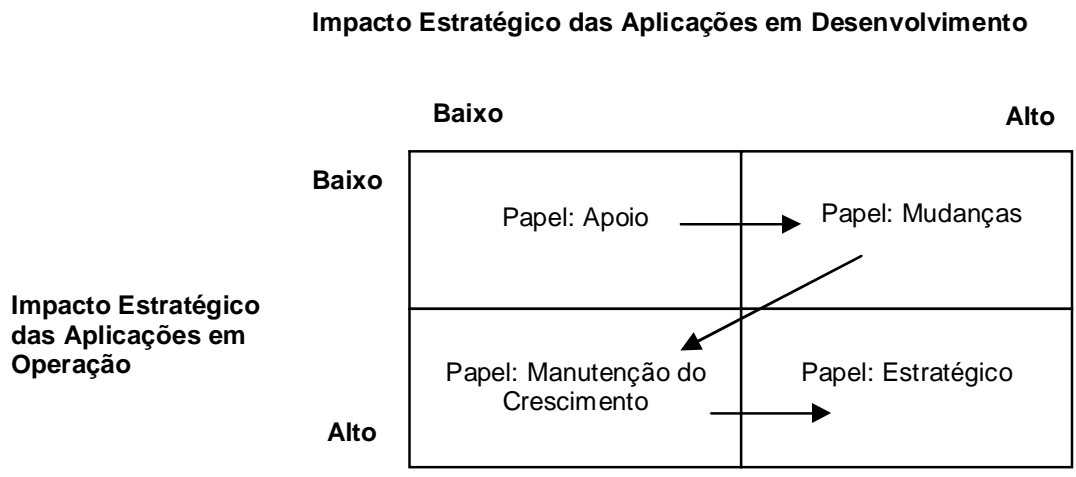

Figura 3: Impacto Estratégico da Tecnologia da Informação.

Fonte: Gerência Estratégica da Tecnologia da Informação (1992, p.37).

> identificação de oportunidades de uso de TI:

Algumas questões-chave devem ser consideradas para a definição de oportunidades estratégicas com o uso da TI: “ A TI pode criar barreiras de entrada? A TI pode reduzir ou eliminar barreiras de entrada? A TI pode reduzir custos de mudança? A TI pode mudar o relacionamento com os fornecedores/ compradores? A TI pode reduzir custos? A TI pode criar diferenciação? A TI pode transformar a cadeia de valor? A TI pode criar novas oportunidades de negócio? A TI pode embutir informação nos produtos? A TI pode adicionar valor continuamente aos produtos e serviços da empresa?” (FERNANDES \& ALVES, 1992, p.41). 
O Modelo de Fernandes \& Alves (1992), possibilita a definição de ações para o alcance dos objetivos e facilita sua utilização, por ser relativamente mais detalhado e por fornecer um check-list do processo de utilização de TI como suporte às estratégias da organização.

O esquema genérico para a avaliação do emprego da TI é ilustrado na figura 4. De acordo com a figura, uma empresa pode empregar a TI visando à eficiência interna, ao processo produtivo e a dependência do consumidor, fornecedor.

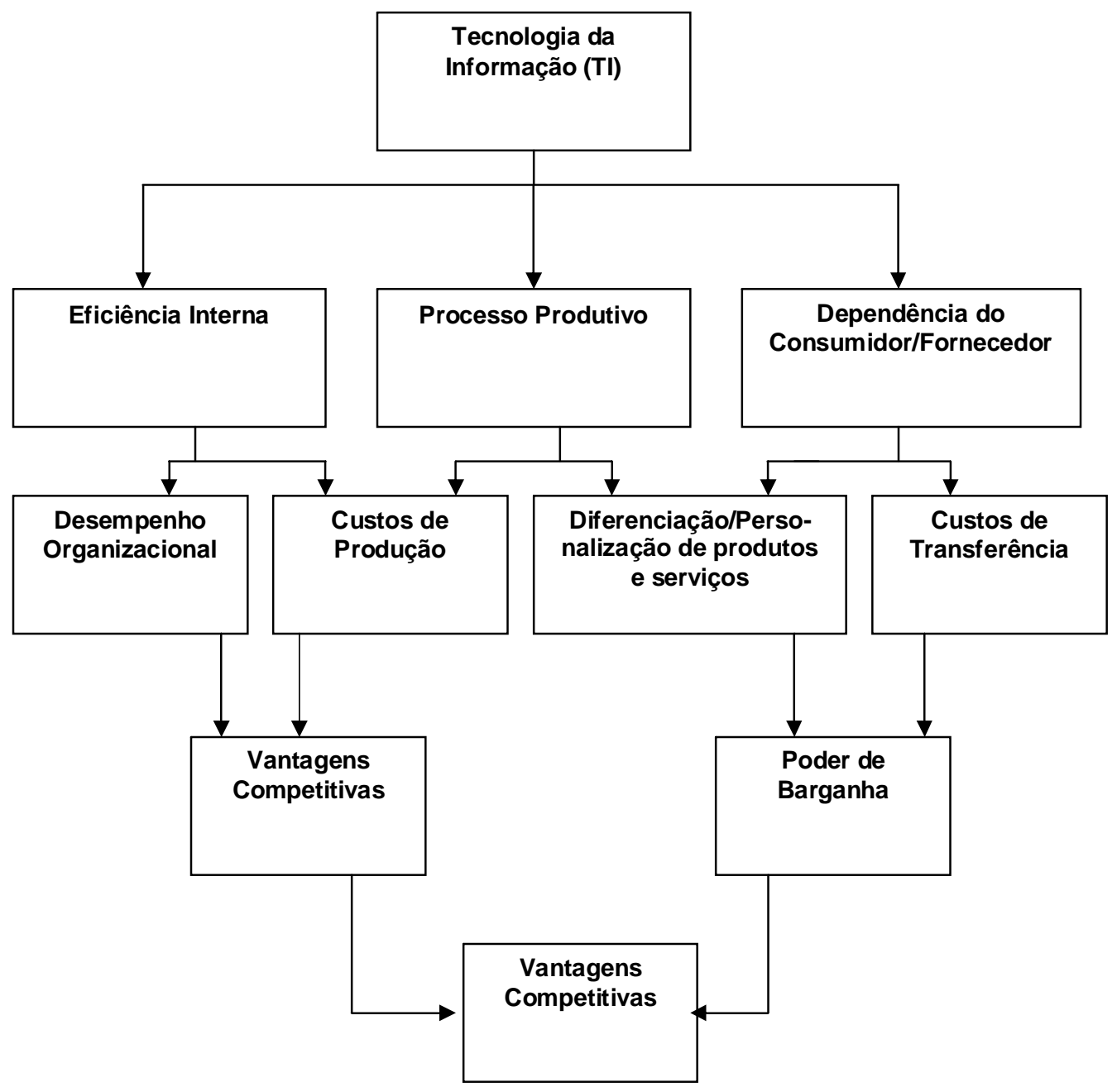

Figura 4: Modelo de Aplicação da Tecnologia da Informação em uma empresa.

Fonte: Gerência Estratégica da Tecnologia da Informação (1992, p.54).

\section{MODELO PROPOSTO}


O modelo proposto é uma combinação do modelo de Gestão Estratégica - Balanced Scorecard (Kaplan e Norton, 1997), com o modelo de Planejamento Estratégico de TI (Fernandes \& Alves, 1992), buscando o alinhamento entre os negócios e atividades de uma pequena empresa desenvolvedora de software, sendo que o modelo proposto utiliza apenas duas etapas do modelo de Fernandes \& Alves, ambas referenciando as metas estabelecidas com o uso do BSC:

1. Definição das Estratégias para a Organização;

2. Identificação do Suporte da TI às Estratégias Propostas pela Organização, subdividida em: Análise dos Impactos da TI e Grau de Dependência Estratégica da Organização com relação a TI.

A primeira etapa consiste em criar as relações de causa e efeito sobre as quatro perspectivas do Balanced Scorecard (Kaplan \& Norton, 1997). Na segunda etapa, a missão e a estratégia serão traduzidas em objetivos e medidas segundo quatro diferentes perspectivas: financeira, do cliente, dos processos internos e do aprendizado e crescimento. A terceira etapa consiste em definir as estratégias (crescimento ou competitividade) que servirão para o alcance dos objetivos da empresa. Na quarta etapa identificaremos o suporte da TI aos impactos da mesma com base nas metas e indicadores das quatro perspectivas do BSC. A quinta etapa consiste na avaliação do grau de dependência da empresa em relação a TI através da Matriz de Dependência Estratégica, proposta por McFarlan, em que para cada conjunto de aplicações há dois níveis de impacto estratégico, alto e baixo e a cada combinação de impacto corresponde um papel para a área de TI da organização. $\mathrm{Na}$ sexta e última etapa, identificaremos as oportunidades estratégicas com o uso da TI sobre as quatro perspectivas do Balanced Scorecard.

A figura 5 ilustra de forma simplificada o conceito do modelo proposto. 


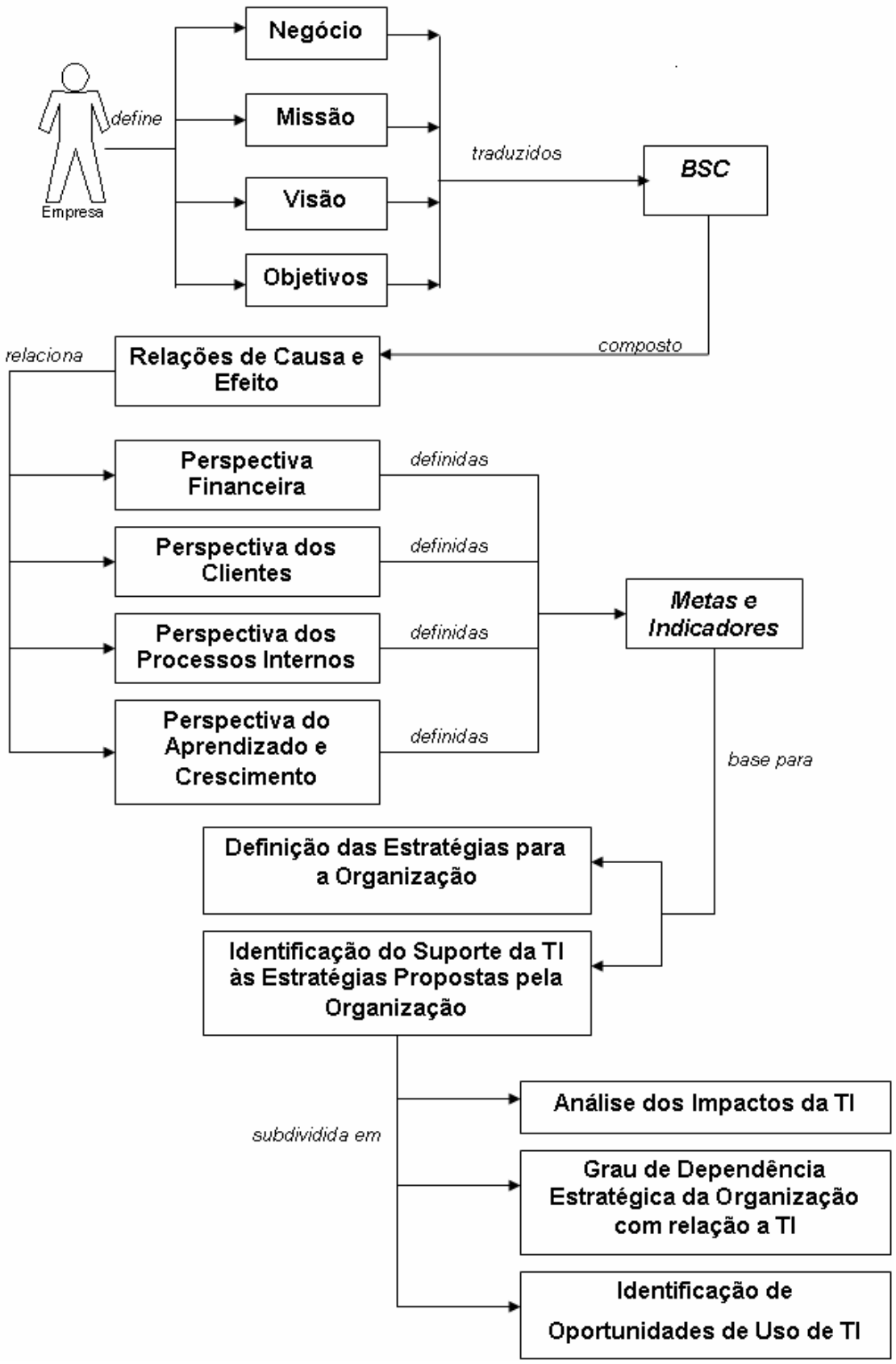

Figura 5: Ilustração simplificada do modelo proposto.

\section{ESTUDO DE CASO}

O estudo de caso iniciou-se a partir da preparação do local de trabalho (na empresa Inside System) com a finalidade de envolver e motivar os colaboradores da empresa. Os questionários foram elaborados através da identificação das informações necessárias para a 
aplicação do modelo proposto e as entrevistas foram pré-agendadas com os diretores e gerentes da empresa. Nas entrevistas alguns conceitos foram explicados verbalmente para que os entrevistados conseguissem responder a algumas questões que envolviam a classificação da empresa em termos técnicos não conhecidos pela mesma.

Após conclusão da proposta de aplicação do modelo proposto, uma nova reunião foi agendada para que pudéssemos verificar a veracidade das informações e objetivos dentro do contexto do modelo, bem como, se a proposta estava de acordo com os negócios da empresa e seus reais objetivos. Sendo o escopo do estudo realizado sobre uma empresa de software, procurou-se adotar um modelo de planejamento estratégico que melhor representasse a realidade da empresa. Alguns modelos eram muito complexos, envolvendo processos industriais, ou utilizavam a estrutura organizacional de uma grande empresa, o que não seria aplicável para esse estudo.

Pequenas empresas, muitas vezes não conseguem aplicar um bom planejamento estratégico, devido ao fato de atualmente não existir um modelo de planejamento estratégico compatível à sua realidade. Assim, precisam aplicar um modelo simples e que objetive os seus interesses e que despendam de baixo custo e curto prazo de implantação e retorno.

\subsection{As Relações de Causa e Efeito.}

Seguindo o modelo proposto, a primeira etapa consistia em criar as relações de causa e efeito sobre as quatro perspectivas do Balanced Scorecard (Kaplan \& Norton, 1997).

A causa do sucesso está diretamente relacionada com as pessoas e as melhorias dos processos da organização abordadas pelo Balanced Scorecard, na perspectiva de aprendizado e crescimento. Essa perspectiva visa à motivação e treinamento de pessoas e processos, com aprendizado contínuo, além de novas visões da empresa, obtidas através de feedback de pessoas, atividades e processos. A cultura organizacional focada no aprendizado e crescimento proporciona o surgimento de questionamentos e sugestões que gerarão mudanças e melhorias dos processos internos.

Os processos internos buscam a implementação e a melhoria soluções para os problemas internos como: maior controle sobre os produtos, desenvolvimento de softwares apoiados em uma metodologia que busque a qualidade do mesmo, assim como melhorar os cronogramas dos projetos, possibilitando dessa forma o aprimoramento dos produtos e serviços oferecidos e a satisfação do seu cliente. Clientes satisfeitos tornam-se leais, motivados e fortalecem sua comunicação com a empresa. Aumentando o nível de satisfação 
do cliente, a empresa aumenta a sua fatia de mercado, o que afeta diretamente os resultados financeiros, como lucro, receita e retorno sobre o investimento.

\subsection{Identificação das Metas e Indicadores para as quatro perspectivas do BSC.}

A segunda etapa do modelo consistia em traduzir a missão e a estratégia em objetivos e medidas, segundo as quatro diferentes perspectivas: financeira, do cliente, dos processos internos e do aprendizado e crescimento. Como visto no quadro 2 abaixo:

Quadro 2: Identificação das Metas e Indicadores dentro das quatro perspectivas do BSC.

\begin{tabular}{|c|c|}
\hline \multicolumn{2}{|c|}{ Identificação das Metas e Indicadores da Perspectiva Financeira } \\
\hline Metas & Indicadores \\
\hline Aumentar o valor agregado & $\begin{array}{l}\text { - \% do investimento dos lucros em reciclagem de } \\
\text { pessoal; } \\
\text { - \% de compra de equipamentos }\end{array}$ \\
\hline Otimizar funções administrativas & $\begin{array}{l}\text { - grau de integração dos sistemas e fácil utilização } \\
\text { dos mesmos por diferentes pessoas; } \\
\text { - grau de administração dos processos } \\
\text { (identificação e escalonação). }\end{array}$ \\
\hline Controlar Fluxo de Caixa de Projetos & $\begin{array}{l}\text { - \% de desperdício de verba por projeto; } \\
\text { - \% sobre a utilização de recursos “fixos" e } \\
\text { "extras"; } \\
\text { - \% do aumento do lucro. }\end{array}$ \\
\hline \multicolumn{2}{|c|}{ Identificação das Metas e Indicadores da Perspectiva do Cliente } \\
\hline Metas & Indicadores \\
\hline Melhorar Cronogramas & $\begin{array}{l}\% \text { dos projetos entregues no prazo, conforme } \\
\text { acordo com o cliente. }\end{array}$ \\
\hline $\begin{array}{l}\text { Melhorar a qualidade de serviços para } \\
\text { alcançar } 100 \% \text { da satisfação dos clientes }\end{array}$ & $\begin{array}{l}\text { - grau de satisfação dos clientes (Feedback dos } \\
\text { clientes). }\end{array}$ \\
\hline Análise de Deficiências & $\begin{array}{l}\text { - \% de problemas encontrados através de testes e } \\
\text { da elaboração de um questionário a ser respondido } \\
\text { pelos clientes. }\end{array}$ \\
\hline \multicolumn{2}{|c|}{ Identificação das Metas e Indicadores da Perspectiva dos Processos Internos } \\
\hline Metas & Indicadores \\
\hline Normatizar processos internos da empresa. & $\begin{array}{l}\text { - Grau de otimização dos recursos e do tempo } \\
\text { gasto para execução das atividades }\end{array}$ \\
\hline Melhorar a área de vendas & $\begin{array}{l}\text { - Grau de eficiência sobre a abordagem em relação } \\
\text { a futuros clientes; } \\
\text { - Grau de direcionamento e foco específico sobre } \\
\text { os produtos e serviços a serem oferecidos. }\end{array}$ \\
\hline $\begin{array}{l}\text { Melhorar a comunicação entre as áreas } \\
\text { dentro da empresa }\end{array}$ & $\begin{array}{l}\text { - Grau de interação e conhecimento das atividades } \\
\text { entre os grupos da empresa de diferentes áreas e }\end{array}$ \\
\hline
\end{tabular}


ISSN 1676 - 1901 / Vol. 6/ Num. 2/ Agosto de 2006

\begin{tabular}{|c|c|}
\hline & projetos \\
\hline Centralizar o controle dos sistemas & $\begin{array}{l}\text { - Grau de otimização e facilidade no controle e } \\
\text { manutenção dos sistemas implantados em clientes }\end{array}$ \\
\hline $\begin{array}{l}\text { Melhorar o processo de alocação de } \\
\text { recursos nos projetos }\end{array}$ & $\begin{array}{l}\text { - Menor tempo em adaptação ao projeto; } \\
\text { - Grau de produtividade e qualidade nos projetos; } \\
\text { - \% de recursos alocados de acordo com suas } \\
\text { competências. }\end{array}$ \\
\hline $\begin{array}{l}\text { Melhorar o processo de planejamento dos } \\
\text { projetos. }\end{array}$ & $\begin{array}{l}\text { - \% de cronogramas ajustados e entregues no } \\
\text { prazo; } \\
\text { - \% de sistemas desenvolvidos com base em } \\
\text { metodologias de software; } \\
\text { - \% de projetos planejados a partir de melhores } \\
\text { análises e eficientes estimativas de custos por } \\
\text { projetos. }\end{array}$ \\
\hline \multicolumn{2}{|c|}{ Identificação das Metas e Indicadores da Perspectiva do Aprendizado e Crescimento. } \\
\hline Metas & Indicadores \\
\hline Cumprimento das metas da missão atual & - Auto-avaliação para a melhoria contínua \\
\hline Reciclar a força de trabalho & - \% de profissionais reciclados e qualificados. \\
\hline Vincular remuneração e desempenho & $\begin{array}{l}\text { - \% de motivação e produtividade em relação aos } \\
\text { funcionários. }\end{array}$ \\
\hline Desenvolver ativos de informação & $\begin{array}{l}\text { - Feedback de informações que fornecerão um } \\
\text { conhecimento para a visão de algo que possa ser } \\
\text { implementado no futuro, visão estratégica. }\end{array}$ \\
\hline $\begin{array}{l}\text { Adicionar características aos produtos e } \\
\text { serviços }\end{array}$ & $\begin{array}{l}\text { - Grau de modificação dos produtos, através do } \\
\text { feedback obtido pelos clientes e funcionários. }\end{array}$ \\
\hline Criar novos serviços a partir dos existentes & $\begin{array}{l}\text { - \% de produtos e serviços originados da } \\
\text { identificação de possíveis oportunidades que o } \\
\text { mercado está requisitando. }\end{array}$ \\
\hline
\end{tabular}

\subsection{Definição das Estratégias para a organização.}

Depois de definidas as metas e os indicadores, a terceira etapa consistia em definir as estratégias. As estratégias servirão para que a empresa alcance os seus objetivos. Fernandes \& Alves (1992), classificam as estratégias empresariais em dois grandes grupos: estratégias de crescimento e estratégias competitivas.

Nesse estudo de caso, a estratégia mais apropriada para o negócio é a estratégia de crescimento, que visa a maior penetração no mercado, desenvolvimento de produtos e diversificação, pois é a que mais retrata os objetivos desejados da empresa como: penetração no mercado nacional, desenvolvimento de novos serviços e soluções.

\subsection{Identificação do Suporte da TI às estratégias propostas pela organização.}


A quarta etapa consistia na identificação do suporte da TI às estratégias propostas pela organização, analisando os impactos que a TI pode ocasionar. Para tanto, como descrito no modelo proposto, analisaremos os impactos da TI com base nas metas e indicadores das quatro perspectivas do BSC.

Quadro 3: Impactos da TI e Aplicações dentro das quatro perspectivas do BSC.

\begin{tabular}{|c|c|c|}
\hline \multicolumn{3}{|c|}{ Perspectiva Financeira } \\
\hline Metas & Impactos da TI & Aplicações \\
\hline Aumentar o valor agregado & $\begin{array}{l}\text { Melhor base tecnológica } \\
\text { para apoio nas atividades } \\
\text { da empresa. }\end{array}$ & $\begin{array}{l}\text { Aquisição de novas tecnologias e } \\
\text { equipamentos. Cursos de } \\
\text { especialização (on-line) }\end{array}$ \\
\hline $\begin{array}{l}\text { Otimizar funções } \\
\text { administrativas }\end{array}$ & $\begin{array}{l}\text { Redução de custos, } \\
\text { otimização do tempo e } \\
\text { padronização de } \\
\text { atividades. }\end{array}$ & $\begin{array}{l}\text { Sistemas independentes serão } \\
\text { integrados e padronizarão os } \\
\text { processos administrativos }\end{array}$ \\
\hline $\begin{array}{l}\text { Controlar Fluxo de Caixa de } \\
\text { Projetos }\end{array}$ & $\begin{array}{l}\text { Controle sobre a verba de } \\
\text { um projeto, redução de } \\
\text { custos e melhor } \\
\text { planejamento na } \\
\text { utilização dos recursos. }\end{array}$ & $\begin{array}{l}\text { Sistema que demonstre o fluxo de } \\
\text { caixa de um projeto, gastos, } \\
\text { verbas disponíveis, recursos } \\
\text { consumidos, etc. }\end{array}$ \\
\hline \multicolumn{3}{|c|}{ Perspectiva do Cliente } \\
\hline Metas & Impactos da TI & Aplicações \\
\hline Melhorar Cronogramas & $\begin{array}{l}\text { Controle das atividades } \\
\text { referentes ao serviço } \\
\text { requisitado pelo cliente, } \\
\text { priorizados pela } \\
\text { necessidade do mesmo. }\end{array}$ & $\begin{array}{l}\text { Acesso via Internet de cadastros } \\
\text { de requisições de serviços pelo } \\
\text { cliente, com possibilidade de } \\
\text { reestruturação de prioridades, } \\
\text { fornecendo também uma forma } \\
\text { para que o gerente do projeto } \\
\text { formalize e administre melhor o } \\
\text { cronograma de atividades. }\end{array}$ \\
\hline $\begin{array}{l}\text { - Melhorar a qualidade de } \\
\text { serviços para alcançar } 100 \% \text { da } \\
\text { satisfação dos clientes. } \\
\text { - Análise de deficiências }\end{array}$ & $\begin{array}{l}\text { Serviços e produtos com } \\
\text { melhor qualidade e que } \\
\text { atendam as expectativas } \\
\text { dos clientes. }\end{array}$ & $\begin{array}{l}\text { Sistema que tenha um check-list a } \\
\text { ser respondido pelo cliente (em } \\
\text { períodos determinados ou ao final } \\
\text { de cada projeto), para que } \\
\text { informações possam ser } \\
\text { armazenadas por um banco de } \\
\text { dados e a partir dessas } \\
\text { informações trabalhar no } \\
\text { melhoramento de processos, } \\
\text { serviços e até mesmo } \\
\text { oferecimento de novos } \\
\text { produtos/serviços. }\end{array}$ \\
\hline \multicolumn{3}{|c|}{ Perspectiva dos Processos Internos } \\
\hline Metas & Impactos da TI & Aplicações \\
\hline Normatizar processos internos & Otimização de recursos, & Automatização de escritório. \\
\hline
\end{tabular}




\begin{tabular}{|c|c|c|}
\hline da empresa. & $\begin{array}{l}\text { tempo e melhor controle } \\
\text { sobre os processos da } \\
\text { empresa. }\end{array}$ & $\begin{array}{l}\text { Integração de sistemas que fazem } \\
\text { o controle interno da empresa } \\
\text { sendo que estabeleça seqüências } \\
\text { para operações e "travamentos" } \\
\text { não permitindo que um processo } \\
\text { avance uma etapa se o anterior } \\
\text { não foi cumprido. }\end{array}$ \\
\hline Melhorar a área de vendas & $\begin{array}{l}\text { Proporcionar uma } \\
\text { abordagem consistente e } \\
\text { maior enfoque aos } \\
\text { produtos e serviços } \\
\text { oferecidos a potenciais } \\
\text { clientes. }\end{array}$ & $\begin{array}{l}\text { Banco de dados com o perfil das } \\
\text { empresas que possam se tornar } \\
\text { futuros clientes. }\end{array}$ \\
\hline $\begin{array}{l}\text { Melhorar a comunicação entre } \\
\text { as áreas dentro da empresa }\end{array}$ & $\begin{array}{l}\text { Quebrar barreiras, criar } \\
\text { novos hábitos entre os } \\
\text { funcionários, facilitar a } \\
\text { comunicação entre } \\
\text { diferentes grupos de } \\
\text { trabalhos alocados em } \\
\text { diferentes locais. }\end{array}$ & $\begin{array}{l}\text { Área comum de acesso por } \\
\text { usuários de diferentes áreas com a } \\
\text { listagem dos projetos de cada um, } \\
\text { compartilhamento e troca de } \\
\text { informação (problemas, soluções, } \\
\text { dicas, sugestões, etc.). }\end{array}$ \\
\hline $\begin{array}{l}\text { Centralizar o controle dos } \\
\text { sistemas }\end{array}$ & $\begin{array}{l}\text { Facilitar a manutenção e o } \\
\text { controle de sistemas } \\
\text { implantados em diferentes } \\
\text { locais. }\end{array}$ & $\begin{array}{l}\text { Programas de acesso remoto, } \\
\text { VPN, etc. }\end{array}$ \\
\hline $\begin{array}{l}\text { Melhorar o processo de } \\
\text { alocação de recursos nos } \\
\text { projetos }\end{array}$ & $\begin{array}{l}\text { Redução de tempo e } \\
\text { redução do custo em } \\
\text { treinamento, do recurso } \\
\text { requisitado, de acordo } \\
\text { com o seu perfil. }\end{array}$ & $\begin{array}{l}\text { Banco de dados com o perfil dos } \\
\text { funcionários da empresa, com as } \\
\text { atividades já executadas, } \\
\text { competências, conhecimento em } \\
\text { ferramentas, habilidade de } \\
\text { trabalho em equipe e em clientes, } \\
\text { avaliação de desempenho, } \\
\text { eficiência, observações realizadas } \\
\text { pelos gerentes de projetos, etc. }\end{array}$ \\
\hline $\begin{array}{l}\text { Melhorar o processo de } \\
\text { planejamento dos projetos. }\end{array}$ & $\begin{array}{l}\text { Melhor enfoque no } \\
\text { planejamento através do } \\
\text { uso da informação. }\end{array}$ & $\begin{array}{l}\text { Banco de dados com informações } \\
\text { sobre clientes e projetos já } \\
\text { realizados ou em andamento, com } \\
\text { comentários úteis sobre } \\
\text { dificuldades, relacionamentos } \\
\text { com usuários, soluções, desafios, } \\
\text { custos estimados, custos gastos, } \\
\text { etc. }\end{array}$ \\
\hline \multicolumn{3}{|c|}{ Perspectiva do Aprendizado e Crescimento } \\
\hline Metas & Impactos da TI & Aplicações \\
\hline $\begin{array}{l}\text { Cumprimento das metas da } \\
\text { missão atual }\end{array}$ & $\begin{array}{l}\text { Controle sobre as } \\
\text { atividades e mudanças } \\
\text { que estão sendo aplicadas } \\
\text { para o alcance das metas. }\end{array}$ & $\begin{array}{l}\text { O impacto da TI nessa perspectiva } \\
\text { se encaixa com a análise, } \\
\text { avaliação e extração de } \\
\text { conhecimento através de }\end{array}$ \\
\hline
\end{tabular}


ISSN 1676 - 1901 / Vol. 6/ Num. 2/ Agosto de 2006

\begin{tabular}{|c|c|c|}
\hline Reciclar a força de trabalho & $\begin{array}{l}\text { Identificar/Escolher os } \\
\text { funcionários que irão } \\
\text { participar pelo processo } \\
\text { de reciclagem. }\end{array}$ & \multirow{5}{*}{$\begin{array}{l}\text { informações e dados existentes } \\
\text { em um banco de dados, que pode } \\
\text { ser criado a partir das informações } \\
\text { bases que são desejadas para } \\
\text { avaliação futuro de desempenho, } \\
\text { lucratividade, etc. }\end{array}$} \\
\hline $\begin{array}{l}\text { Vincular remuneração e } \\
\text { desempenho }\end{array}$ & $\begin{array}{l}\text { Melhor julgamento sobre } \\
\text { cada funcionário. }\end{array}$ & \\
\hline $\begin{array}{l}\text { Desenvolver ativos de } \\
\text { informação }\end{array}$ & $\begin{array}{l}\text { Facilidade no } \\
\text { armazenamento e } \\
\text { recolhimento de dados } \\
\text { que serão transformados } \\
\text { em informação. }\end{array}$ & \\
\hline $\begin{array}{l}\text { Adicionar características aos } \\
\text { produtos e serviços }\end{array}$ & $\begin{array}{l}\text { Análise crítica e } \\
\text { visionários sobre a base } \\
\text { de dados dos produtos e } \\
\text { serviços. }\end{array}$ & \\
\hline $\begin{array}{l}\text { Criar novos serviços a partir } \\
\text { dos existentes }\end{array}$ & $\begin{array}{l}\text { Análise visionário sobre o } \\
\text { comportamento do } \\
\text { mercado com base em } \\
\text { dados e informações do } \\
\text { mesmo. }\end{array}$ & \\
\hline
\end{tabular}

\subsection{Grau de Dependência da TI}

A avaliação do grau de dependência da empresa em relação a TI através da Matriz de Dependência Estratégica, proposta por McFarlan (FERNANDES \& ALVES, 1992, p.35), é realizada na quinta etapa, onde para cada conjunto de aplicações há dois níveis de impacto estratégico, alto e baixo e a cada combinação de impacto corresponde um papel para a área de TI da organização.

A matriz de dependência estratégica foi criada primeiramente sob a ótica da organização como um todo (de forma genérica), ilustrada na figura 6 , e mais tarde um quadro sobre a perspectiva atual (posição das metas antes da aplicação do modelo), foi criado, para se visualizar mais facilmente a dependência estratégica de cada meta. A matriz é obtida através do enquadramento da empresa frente a uma avaliação e questionamentos propostos por Fernandes \& Alves (1992). Contundo a empresa Inside System foi classificada como: Impacto Estratégico das aplicações em desenvolvimento: Alto, e Impacto Estratégico das aplicaçães em operação: Baixo.

Analisando o estudo de caso em questão, pode-se dizer que a TI desempenhava um papel de mudanças (figura 6), pois a estratégia empresarial depende dos sistemas que estão em operação, mas não é colocada como peça vital aos funcionamentos dos mesmos, no entanto a empresa procura que os sistemas em desenvolvimento alcancem os objetivos 
estratégicos da organização. Portanto atualmente pode-se dizer que a empresa encontra-se inserida na matriz de dependência estratégica (figura6), no papel de mudanças. O que a empresa busca futuramente com a normatização dos processos, implantação do planejamento estratégico (figura 6) e inclusão de metodologias nos processos de desenvolvimento de software, é passar do papel de mudanças para o estratégico, onde a estratégia empresarial depende do bom funcionamento, tanto dos sistemas em operação como dos que se encontram em desenvolvimento.

Impacto Estratégico das Aplicações em Desenvolvimento
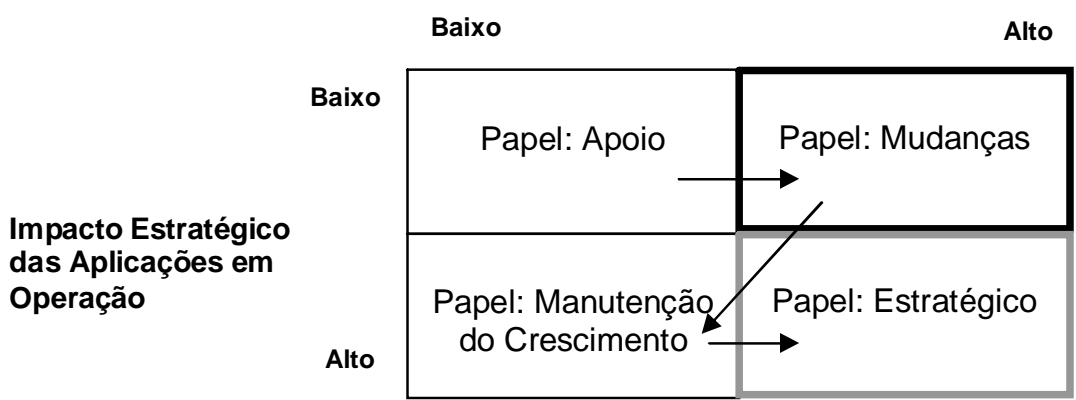

Figura 6: Dependência estratégica da TI na organização (vista como um todo).

O quadro 4 mostra a classificação da atual situação da empresa do ponto de vista da dependência estratégica da TI, nas quatro perspectivas do BSC. Com esse quadro a empresa consegue visualizar facilmente a sua posição atual e as transições que deverá sofrer futuramente, para alcançar um novo papel de dependência.

Quadro 4: Classificação das metas sobre o ponto de vista da dependência estratégica, dentro das quatro perspectivas do BSC.

\begin{tabular}{|l|c|c|c|c|}
\hline \multicolumn{4}{|c|}{ Perspectiva Financeira } \\
\hline \multicolumn{1}{|c|}{ Metas } & Apoio & Mudanças & $\begin{array}{c}\text { Manutenção e } \\
\text { Crescimento }\end{array}$ & Estratégico \\
\hline $\begin{array}{l}\text { Aumentar o valor } \\
\text { agregado }\end{array}$ & & $\mathrm{X}$ & & \\
\hline $\begin{array}{l}\text { Otimizar funções } \\
\text { administrativas }\end{array}$ & $\mathrm{X}$ & $\mathrm{X}$ & & \\
\hline $\begin{array}{l}\text { Controlar Fluxo de } \\
\text { Caixa de Projetos }\end{array}$ & Perspectiva do Cliente \\
\hline \multicolumn{2}{|c|}{} \\
\hline
\end{tabular}


ISSN 1676 - 1901 / Vol. 6/ Num. 2/ Agosto de 2006

\begin{tabular}{|c|c|c|c|c|}
\hline & \multicolumn{4}{|c|}{ Papel (Dependência Estratégica) } \\
\hline Metas & Apoio & Mudanças & $\begin{array}{l}\text { Manutenção e } \\
\text { Crescimento }\end{array}$ & Estratégico \\
\hline Melhorar Cronogramas & & & & $\mathrm{X}$ \\
\hline $\begin{array}{l}\text { - Melhorar a qualidade } \\
\text { de serviços para alcançar } \\
100 \% \text { da satisfação dos } \\
\text { clientes. }\end{array}$ & & $\mathrm{X}$ & & \\
\hline - Análise de deficiências & & & & \\
\hline \multicolumn{5}{|c|}{ Perspectiva dos Processos Internos } \\
\hline & \multicolumn{4}{|c|}{ Papel (Dependência Estratégica) } \\
\hline Metas & Apoio & Mudanças & $\begin{array}{l}\text { Manutenção e } \\
\text { Crescimento }\end{array}$ & Estratégico \\
\hline $\begin{array}{l}\text { Normatizar processos } \\
\text { internos da empresa. }\end{array}$ & $\mathrm{X}$ & & & \\
\hline $\begin{array}{l}\text { Melhorar a área de } \\
\text { vendas }\end{array}$ & & $\mathrm{X}$ & & \\
\hline $\begin{array}{l}\text { Melhorar a comunicação } \\
\text { entre as áreas dentro da } \\
\text { empresa }\end{array}$ & & $\mathrm{X}$ & & \\
\hline $\begin{array}{l}\text { Centralizar o controle } \\
\text { dos sistemas }\end{array}$ & & $\mathrm{X}$ & & \\
\hline $\begin{array}{l}\text { Melhorar o processo de } \\
\text { alocação de recursos nos } \\
\text { projetos }\end{array}$ & & $\mathrm{X}$ & & \\
\hline $\begin{array}{l}\text { Melhorar o processo de } \\
\text { planejamento dos } \\
\text { projetos. }\end{array}$ & & & & $\mathrm{X}$ \\
\hline \multicolumn{5}{|c|}{ Perspectiva do Aprendizado e Crescimento } \\
\hline & \multicolumn{4}{|c|}{ Papel (Dependência Estratégica) } \\
\hline Metas & Apoio & Mudanças & $\begin{array}{l}\text { Manutenção e } \\
\text { Crescimento }\end{array}$ & Estratégico \\
\hline $\begin{array}{l}\text { Cumprimento das metas } \\
\text { da missão atual }\end{array}$ & & & & $\mathrm{X}$ \\
\hline $\begin{array}{l}\text { Reciclar a força de } \\
\text { trabalho }\end{array}$ & & $\mathrm{X}$ & & \\
\hline $\begin{array}{l}\text { Vincular remuneração e } \\
\text { desempenho }\end{array}$ & $X$ & & & \\
\hline $\begin{array}{l}\text { Desenvolver ativos de } \\
\text { informação }\end{array}$ & & $X$ & & \\
\hline $\begin{array}{l}\text { Adicionar características } \\
\text { aos produtos e serviços }\end{array}$ & & & $\mathrm{X}$ & \\
\hline $\begin{array}{l}\text { Criar novos serviços a } \\
\text { partir dos existentes }\end{array}$ & & & & $\mathrm{X}$ \\
\hline
\end{tabular}

\subsection{Identificação das Oportunidades Estratégicas com o Uso da TI.}


Na sexta e ultima etapa identificamos as oportunidades estratégicas com o uso da TI. Para identificar tais oportunidades estratégicas, a análise foi realizada baseada nas quatro perspectivas do Balanced Scorecard.

\section{a) Perspectiva Financeira}

A aplicação de TI visando melhorar o controle e fluxo de caixa, além de otimizar funções administrativas. Nesse sentido, alguns exemplos de aplicação de TI na Inside System podem ser vistos:

- Sistema de controle financeiro (MS Money, Planilhas, etc.);

- Intranet (controle de fluxo de caixa por projeto), possibilitando um melhor controle de gastos em relação aos recursos pelos gerentes de projetos;

- Sistema de automação de escritórios, possibilitando a redução de custos burocráticos e aumentando a produtividade.

b) Perspectiva dos Clientes

A aplicação de TI, visando melhorar o relacionamento entre a empresa e seus clientes, criando uma comunicação eficiente e buscando a competência em seus produtos e serviços. A seguir alguns exemplos de aplicação de TI na Inside System:

- Check-list (questionários) de satisfação do cliente (on-line);

- Sistema on-line que permita: o requerimento de serviços, cadastrado diretamente pelos clientes, a reorganização do cronograma pelo cliente de acordo com suas prioridades, o acompanhamento das atividades e os recursos alocados para os serviços requeridos, etc.;

c) Perspectiva dos Processos Internos

A aplicação de TI, visando melhorar os processos internos da empresa, buscando a otimização de serviços, o aumento a competitividade e o alinhamento dos processos existentes. Seguem alguns exemplos de aplicação de TI na Inside System:

- Sistemas remotos (VNC, VPN, etc.);

- Intranet;

- Bases de dados;

- Usos de ferramentas para controle dos projetos (MS Project);

- Datawarehouse; 
d) Perspectiva do Aprendizado e Crescimento

A aplicação de TI, visando o aprendizado e crescimento através de experiências passadas, sugestões e motivação. Nesse sentido, alguns exemplos de aplicação de TI na Inside System podem ser observados:

- Base de dados;

- Intranet;

- Check-list/Questionário (on-line).

A empresa Inside System já utiliza algumas aplicações de TI como: sistema financeiro em Delphi e Access; Planilhas com macros para folha de pagamentos, controle financeiro; Intranet com várias funcionalidades entre outras que serão implementadas para suprir as necessidades da empresa.

O principal sistema de auxílio será a intranet, que já possui:

- Controle de Atividades;

- Manuais guias e normas;

- Agenda de telefones;

- Cadastro de contatos (empresas).

E procurará implementar futuramente as seguintes funcionalidades:

- Controle de projetos;

- Log dos controles de atividades (caso existir uma alteração pelos gerentes);

- Permitir que o próprio cliente cadastre as requisições de serviços;

- Check-list/Questionários para obtenção de feedback (clientes e funcionários);

- Auxílio em funções administrativas (notas fiscais, registro de pedidos de serviços, etc.);

- Cadastro de informações (Base de dados), para análise dos projetos já realizados e os em andamento (cronogramas, clientes, produtos, problemas, soluções);

- Cadastro de informações (Base de dados), para análise do perfil e comportamento dos funcionários em relação a suas competências e observações sobre os projetos que estão envolvidos; 
- Banco de currículos (por área, linguagens, observações e comentários de pessoas já entrevistadas, etc.);

- Controle do fluxo de caixa por projeto (feito pelo gerente do projeto).

\section{CONCLUSÕES}

Através da pesquisa sobre estratégias e planejamentos; verificação do aumento de competitividade; e vivência dos problemas encontrados em pequenas empresas de desenvolvimento de software pode-se concluir que a vantagem competitiva não pode ser obtida apenas com a rápida alocação de novas tecnologias. Com o barateamento das mesmas, o diferencial é obtido através da forma com que as tecnologias e as informações serão aplicadas e trabalhadas. Nesse sentido, o presente trabalho propôs um modelo de planejamento estratégico, avaliação e suporte de TI às estratégias da organização; para que pequenas empresas de desenvolvimento de software pudessem obter a vantagem competitiva que procuram.

Selecionar os conceitos que fariam parte do estudo foi um dos desafios encontrados. Após vasta pesquisa sobre os conceitos e metodologias existentes, constatou-se que não existia nenhum modelo que se ajustasse perfeitamente ao escopo do estudo. Os modelos existentes muitas vezes eram complexos, trabalhosos, visavam mudanças em longo prazo; não se encaixando na realidade da empresa em estudo (pequena empresa de desenvolvimento de software), tornando-se assim inviáveis. Portanto priorizamos conceitos e metodologias mais genéricas, simples e de fácil aplicabilidade ao estudo.

Em relação ao modelo utilizado, pode-se dizer que foi prático, objetivo e de fácil aplicação, o que motivou a empresa na adoção de um planejamento estratégico. É importante ressaltar que é indispensável que a empresa entenda em que implica a implantação desses conceitos, arcando com as responsabilidades, os deveres, o $\mathrm{RH}$; para que o planejamento estratégico seja bem sucedido. Apesar das limitações, desafios, e dificuldades encontradas pode-se dizer que a pesquisa é válida, já que procura adotar uma nova prática dentro de empresas de pequeno porte (desenvolvedoras de software).

O modelo proposto permite visualizar mais facilmente o uso estratégico da TI nos negócios da empresa (estratégias da empresa), ou seja, o modelo tem a intenção de facilitar a escolha certa de aplicações de TI para que a empresa alcance com sucesso seus objetivos e metas, além de possibilitar os pontos a serem atacados, quais as melhores ferramentas para 
determinados problemas, projeção de cronograma e orçamento para a implementação das soluções.

Para uma contribuição mais significativa, recomenda-se o acompanhamento da implantação do modelo proposto e uma análise final com os resultados obtidos, assim como a aplicação do mesmo em outras organizações, com o objetivo de aprimorá-lo. Um aplicativo de apoio pode ser também desenvolvido, com base em um modelo de negócios.

\section{REFERÊNCIAS}

BALANCED SCORECARD INSTITUTE. Disponível em: <http://www.balancescoredcard.org.br/bscand/bsckm.html>. Acesso em 20 de Junho de 2005.

BEAL, ADRIANA, A importância do Planejamento de T.I., 2001.

FERNANDES, AGUINALDO A.; ALVES, MURILO M., Gerencia estratégica da tecnologia da informação. Rio de Janeiro: Livros Técnicos e Científicos, 1992.

FORMA INFORMÁTICA. Metodologia - Planejamento Estratégico da Informação incorporando tecnologia ao Negócio, 2003.

KAPLAN, ROBERT S.; NORTON, DAVID P. A estratégia em ação: Balanced scorecard. Rio de Janeiro: Campus, 1997.

MINTZBERG, H. Generic Strategies: Toward a Comprehensive Framework. In: SHRIVASTAVA, P. (Ed.) Advances in Strategic Management. Greenwich, Conn: Jay Press, 1988.

PORTER, MICHAEL E., Estratégia Competitiva - Técnicas para Análise de Indústrias e da Concorrência. Rio de Janeiro: Campus, 1996. 
PORTER, MICHAEL E., Vantagem competitiva: Criando e Sustentando um

Desempenho Superior, Rio de Janeiro: Campus: 1992.

PORTER, MICHAEL E., Competitive Advantage, New York: Free Press, 1985.

PORTER, MICHAEL E., How competitive forces shape strategy, Harvard Business Review: 1979

SUZUKI, ÉRIKA, Alinhamento Estratégico aos Negócios para uma Pequena Empresa de Software, TCC - Sistemas de Informação, Universidade Federal de Santa Catarina, 2004.

TREACY, MICHAEL; WIERSEMA, FRED. A disciplina dos líderes de mercado: escolha seus cliente, direcione seu foco, domine seu mercado. 3 ed. Rio de Janeiro: Rocco, 1995.

TURBAN, EFRAIN; MACLEAN, EPHRAIN; WETHERBE, JAMES. Information Technology for Management Improving Quality and Productivity, New York: John Wiley \& Sons, 1996.

Artigo recebido em 01/07/2005 e aceito para publicação em 07/08/2006 